\title{
Luces y sombras: Excelsior en Argentina y el humo del progreso
}

\author{
( Ignacio González \\ Universidad de Buenos Aires/Universidad Nacional de las Artes/ Centro Cultural de La Coo- \\ peración “Floreal Gorini”, Argentina \\ igonzalez@uba.ar
}

Fecha de recepción: 30/04/2020. Fecha de aceptación: 14/07/2020

\section{Resumen}

En los distintos estudios sobre historia de la danza en Argentina, el ballet italiano Excelsior ha sido escasamente desarrollado. Hasta el momento no hay publicaciones que hayan estudiado con mayor detenimiento ni la escenificación de Excelsior en Argentina en 1883 ni tampoco las versiones siguientes. Este primer acercamiento tiene dos objetivos iniciales: dar cuenta de la versión modelo del ballet, estrenada en el Teatro alla Scala de Milán en 1881, a partir del análisis de documentos como así también de las últimas investigaciones académicas disponibles, y utilizar Excelsior como punto de partida para abordar el análisis de un período histórico de la Argentina: $1880-1916$.

Palabras clave: Excelsior, Ballo Grande, Argentina, progreso, Teatro Colón.

\section{Lights and Shadows: Excelsior in Argentina and the Smoke of Progress}

\begin{abstract}
The famous Italian ballet Excelsior has been scarcely studied in the different works on dance history in Argentina. Until now, there are no publications that have studied in greater detail neither the staging of Excelsior in Argentina in 1883, nor its following versions. This first approach has two initial objectives: to account for the "model" version of the ballet -premiered at the Teatro alla Scala in Milan in 1881-based on the analysis of documents and on the latest available academic research, and to use Excelsior as a starting point to approach the analysis of a historical period of Argentina: 1880-1916.
\end{abstract}

Keywords: Excelsior, Ballo Grande, Argentina, progress, Colón Theater. 


\section{Introducción}

El 6 de septiembre de 1883 se presentó en Buenos Aires, en el primer Teatro Colón, el ballet italiano Excelsior de Luigi Manzotti, con música de Romualdo Marenco. Este ballo grande había sido estrenado en el Teatro alla Scala de Milán dos años antes. Como menciona Sergia Adamo (2014), entre 1881 y la muerte de Manzotti en 1905, Excelsior se presentó con gran éxito más de cincuenta veces en diferentes teatros y ciudades. Inclusive inauguraba, en 1883 , un nuevo teatro en París construido especialmente para dar lugar a este tipo de espectáculos, el Éden-Théâtre. El ballet no sólo tuvo una première parisina, sino que se escenificó ese mismo año en Madrid, Valencia, Nueva York, Varsovia, Berlín, Río de Janeiro y Buenos Aires (158).

La circulación internacional del ballet brinda claves para entender no sólo su éxito, sino además la expansión imperialista de los discursos que este ballet llevaba consigo, vinculados a los progresos técnicos alcanzados en Occidente. En la nueva configuración mundial de los territorios del globo, Excelsior aparece como carta de presentación de la modernización capitalista. En ese sentido, presentar este espectáculo en un país puede pensarse como un intento por incluir a la nación en cuestión en un proyecto modernizador de alcance global. Este ballo grande, podríamos decir, pierde su lugar de origen (Italia) para ser reapropiado -inclusive con mínimos cambios- en los territorios de sus sucesivas escenificaciones: Excelsior no habla particularmente de Italia, sino más bien del país donde se representa.

Si escenificar este ballet ubicaba a las naciones en un discurso modernizador, también señalaba, muchas veces, sus tensiones internas. La hipótesis que mantendremos en este trabajo es que si, por un lado, la circulación internacional de Excelsior podría parecer que ubicaba al mismo nivel de progreso a las naciones en las que se escenificaba -en sus diversas versiones-, por otro lado, pondría en evidencia los conflictos de ese proceso modernizador al ser una meta a alcanzar. En el caso de Argentina, el hecho de traer el ballet al país significará un intento por establecer una sincronía cultural con aquellas ciudades de los países europeos dominantes, pero el contenido utópico del ballet denunciará, o más bien señalará, las contradicciones en un país que, en lo concreto, se estructura en sus relaciones con el mundo bajo una situación de dependencia.

Los datos recopilados señalan, al menos, tres momentos en los que se escenificó Excelsior en Buenos Aires: en el año 1883, en 1886 y en 1916. A partir del inicio de la Primera Guerra Mundial en 1914, el conflicto bélico incidirá en el contenido del ballet, y escenificar Excelsior ya no tendrá el mismo significado. Por una cuestión de extensión y por la documentación con la que contamos hasta el momento, focalizaremos en este trabajo en la versión del año 1883 y en la de 1916. Realizaremos solamente algunas notas en referencia a la versión de 1886 . Son muy pocos los libros, artículos o investigaciones consultados sobre danza en Argentina que hagan mención a esa versión en el viejo Teatro Colón de Buenos Aires. Hasta el momento hallamos que aparece mencionada en Sala (1969: 111) y en Destaville (2008: 23-24). Según nuestra investigación, sobre la escenificación de 1886 se realizaron once funciones del ballet en el mes de agosto. En las secciones "Diversiones Públicas" del periódico El Mosquito pudimos corroborar el dato. Allí se publicitaba, por ejemplo: "Compañía Coreográfica - Empresa de A. Ferrari". El director de la orquesta era Enrique Bovi y el ballet Excelsior aparecía estructurado en "3 actos y 9 cuadros" (Anónimo, 8/08/1886: s/p). Inclusive en la sección "Teatros" del mismo periódico se hacía un breve comentario sobre el ballet.

En los distintos estudios sobre historia de la danza en Argentina (Malinow, 1962; Giovannini, y Foglia de Ruiz, 1973; Durante, 2008), Excelsior ha sido escasamente 
desarrollado. En general, parece ocupar el lugar de antecedente en un relato de la historia de la danza que ve su comienzo en 1913, con la primera visita de los Ballets Russes (Tambutti, 2011, 2015). En ese sentido, la versión de Excelsior que aparece dentro de ese relato es la de 1916. Si bien la primera vez que llega este ballet al país aparece como referencia en esa historia de llegadas o de visitas de compañías extranjeras a la Argentina, hasta el momento no hay publicaciones que hayan estudiado con mayor detenimiento ni la de 1883 ni tampoco las versiones siguientes.

Esto puede deberse a varias cuestiones, como por ejemplo, al lugar marginal de la historia de esta disciplina. Como menciona María José Cifuentes, incluso la danza ha sido frecuentemente omitida de "los corpus oficiales de la historia del arte" (2008: 86), atribuyendo esta omisión al carácter ontológico, efímero, de la danza en tanto arte (que conlleva a la idea de que la danza escapa a toda forma de registro y documentación). Pero otra razón podemos encontrarla en el estado precario o inexistencia de los archivos de danza en los países latinoamericanos. Por lo tanto, no es casual que lo que se pueda decir de Excelsior, por ejemplo, sea una repetición de los pocos datos disponibles sobre la obra en este país.

Por esa razón, este trabajo tiene dos objetivos iniciales: en primer lugar, dar cuenta de la versión modelo del ballet, estrenada en el Teatro alla Scala de Milán en 1881, a partir del análisis de documentos disponibles, como así también de las últimas investigaciones académicas. En segundo lugar, utilizar a Excelsior, en sus distintas escenificaciones en Buenos Aires, como punto de partida para abordar el análisis de un período de la historia del país: 1880-1916.

En términos metodológicos, complementaremos un análisis de la reconstrucción del ballet con otro de su período histórico para no perder de vista el contexto económico, social y cultural del momento. Para ello, una mirada de reojo a la prensa de ese tiempo, también aportará claves para contextualizar el ballet en los días de su representación y comprender un marco que va más allá de una historia formalista de la danza. En un primer punto, intentaremos reponer la historia de Excelsior y su circulación internacional. En el segundo punto trabajaremos sobre el período 1880-1916 en Argentina y los estrenos de Excelsior en la ciudad de Buenos Aires.

\section{Excelsior: el ballo grande y el internacionalismo}

Excelsior se estrenó el 11 de enero de 1881 en el Teatro alla Scala de Milán y rápidamente se transformó en un suceso balletístico, estableciéndose como una de las obras más famosas del siglo y de la historia de la danza occidental. Nueve días después del estreno en Milán, la noticia había llegado a Madrid. El diario La Iberia, por ejemplo, decía: "el baile Excelsior ha iniciado un género especial que seguramente será seguido por los principales teatros de Europa" (Anónimo, 1881, 20 de enero: 4).

El ballet se inscribía en la tradición teatral italiana de la segunda mitad del siglo XIX conocida como ballo grande. Como menciona Sergia Adamo, este género consistía en escenas grandiosas, con patrones narrativos simples y evidentes intenciones didácticas (2014: 164). A la grandiosidad de las escenografías se le sumaba un enorme número de performers y, en ocasiones, también animales. Además, se mezclaba la técnica de la danza clásica, las danzas de carácter, la pantomima, danzas populares y otras formas de movimiento y mostraciones de virtuosismo, como la acrobacia y el malabarismo. Como dato un poco gracioso, el corderito Pepito aparece fotografiado, junto a otros animales, en la revista Caras y Caretas del 5 de agosto de 1916. El animal formó parte de Excelsior cuando se presentó en el nuevo Teatro Colón ese año (Allende: 1916). 
No es del todo curioso, por lo tanto, que haya sido un monumento el punto de partida de una obra con características monumentales (en Excelsior participaban más de 500 artistas, entre bailarines, mimos, acróbatas, músicos, etc.). Como menciona el propio Luigi Manzotti:

Vi el monumento erigido en Turín en gloria del portentoso túnel del Cenis e imaginé la composición coreográfica actual.

Es la lucha titánica sostenida por el Progreso contra el Retroceso [Regresso] lo que presento a este público inteligente: es la grandeza de la Civilización que gana, vence, destruye, para el bien de los pueblos, el antiguo poder del Oscurantismo que los mantuvo en la oscuridad de la servidumbre e ignominia.

A partir de la era de la Inquisición de España, llego al túnel del Cenis, mostrando los portentosos descubrimientos, las gigantescas obras de nuestro siglo. (Manzotti y Marenco, 1881: 1).

[Las traducciones son mías, en caso que se indique lo contrario. En el original italiano, se lee: "Vidi il monumento innalzato a Torino in gloria del portentoso traforo del Cenisio ed immaginai la presente composizione coreografica"]

Efectivamente, el argumento de Excelsior puede resumirse en el triunfo de la Luz en su lucha contra el Oscurantismo. Estos eran, precisamente, los personajes alegóricos principales del ballet. La estructura externa de la obra consistía en seis partes y once cuadros:

\begin{tabular}{|c|c|c|c|c|c|}
\hline Parte I & Parte II & Parte III & Parte IV & Parte V & Parte VI \\
\hline $\begin{array}{l}\text { Cuadro I: El } \\
\text { Oscurantismo. }\end{array}$ & $\begin{array}{l}\text { Cuadro III: El } \\
\text { primer barco de } \\
\text { vapor }\end{array}$ & $\begin{array}{l}\text { Cuadro V: } \\
\text { El genio del } \\
\text { electricismo. }\end{array}$ & $\begin{array}{l}\text { Cuadro VII: El } \\
\text { Simún. }\end{array}$ & $\begin{array}{l}\text { Cuadro IX: La } \\
\text { última mina. }\end{array}$ & $\begin{array}{l}\text { Cuadro XI: } \\
\text { Apoteosis. } \\
\text { Civilización, }\end{array}$ \\
\hline $\begin{array}{l}\text { Cuadro II: La } \\
\text { luz. }\end{array}$ & $\begin{array}{l}\text { Cuadro IV: } \\
\text { Prodigio de la } \\
\text { Invención. }\end{array}$ & $\begin{array}{l}\text { Cuadro VI: } \\
\text { Efectos de la } \\
\text { electricidad. }\end{array}$ & $\begin{array}{l}\text { Cuadro VIII: } \\
\text { El Canal de } \\
\text { Suez. }\end{array}$ & $\begin{array}{l}\text { Cuadro X: } \\
\text { Oscuridad, Luz } \\
\text { y Gloria. }\end{array}$ & $\begin{array}{l}\text { Progreso, } \\
\text { Concordia. }\end{array}$ \\
\hline
\end{tabular}

La acción dramática desarrollaba la confrontación entre la Luz y el Oscurantismos en distintos lugares (España, Alemania, Estados Unidos, Italia, Egipto...) y establecía un orden casi cronológico de los acontecimientos (desde la Inquisición española hasta el presente), a partir de la mostración de ciertos inventos y construcciones importantes para la humanidad: la máquina de vapor, la locomotora, el barco a vapor, la pila eléctrica, el telégrafo, el Canal de Suez, el túnel ferroviario del Monte Cenis, entre otros. Según se lee en el libreto, así comenzaba el primer cuadro del ballet:

Noche siniestra y fúnebre; un silencio lúgubre solamente interrumpido, a intervalos, por una canción lejana, una canción de melancolía y tristeza acompañada por los repiquetes mesurados de una campana que nos invita a rezar por la última hora de los infelices. Chatarra y ruinas por todas partes, y enormes hogueras y calderas a la distancia. (Manzotti y Marenco, 1881: 6)

[En el original: "Notte sinistra e funebre; lugubre silenzio interrotto soltanto, ad intervalli, da un lontano canto, canto di melanconia e di tristezza accompagnato dai rintocchi misurati di una campana che invita a pregare per l'ultima ora degli infelici. Rottami e rovine ovunque, e roghi e caldaie gigantesche in lontananza".]

En ese ambiente oscuro, desesperanzador y decadente, la Luz aparece encadenada a los pies del Oscurantismo, que se burla de ella. Sin embargo, la Luz vaticina el final del Oscurantismo y los cuadros que siguen consistirán en mostrarle sus futuras glorias, 
a través de los inventos y descubrimientos científicos, que aquel intentará impedir. Entre los personajes se incluían, además de personajes alegóricos (personificaciones de abstracciones: Luz, Oscurantismo, Civilización, Ciencia, Fuerza, Invención, Agricultura, Industria, etc.), personajes históricos, como Dionisio Papin (creador de la máquina de vapor), Alessandro Volta (inventor de la pila eléctrica) y Robert Fulton (quién construyó el primer barco de vapor comercial).

Según el libreto, distintas danzas se distribuían en la obra, en los cuadros II, III, VI, VII y XI. El cuadro II titulado "La luz" sucede en la casa del Genio y de la Ciencia, un lugar deslumbrante de riqueza y esplendor en el que se ven "las grandezas artísticas de todas las épocas" y aparecen escritas en caracteres de oro "el tesoro científico de la época moderna": Vapor, Telégrafo, Suez, Cenis. Los personajes alegóricos danzan simbolizando el triunfo de la modernidad. Las danzas son: $\mathrm{La}$ Fama. Danza para los primeros ocho "estudiantes"; $2^{\circ}$ La Civilità, variación para la primera bailarina absoluta; $3^{\circ} \mathrm{Il}$ Risorgimento. Danza de los Genios de la Fama, Constanza, Concordia, Valor, Invención, Amor, Unión y Fuerza para el Cuerpo de Baile entero y la primera bailarina.

Si bien no es posible saber cómo realmente fue el ballet, y este sufrió constantes modificaciones, existe un documento que puede dar una idea aproximada de la primera parte. Nos referimos al film homónimo realizado en 1913 por Luca Comerio. La coreografía para el film fue realizada por Enrico Biancifiori, y estaba basada en la puesta en escena de Achille Coppini realizada para La Scala hacia fines de 1908. Flavia Pappacena compara esta versión con otras notaciones escritas del ballet, y dice: "Civilisation's entrance (diagonal and salutation) conforms to the Cecchetti version. The series of steps in the Resurgence Dance is almost identical to the Cammarano version ... with increased difficulty: gargouillades in the first series (from the Galimberti jumped on points), ronds de jambe en l'air sautés in the third series, but échappé with changements sautés sur les pointes (Galimberti) in place of the entrechat quatre-échappé(Cammarano) in the second series (the withdrawal)" (citada en Pritchard, 2001: 110). Puede observarse, de esa manera, cómo la versión fílmica condensa distintas reelaboraciones coreográficas.

En el film de Comerio, pueden observarse, en los únicos catorce minutos que perduraron, el primer cuadro pantomímico (filmado al aire libre, en Precotta) y las danzas del segundo cuadro (registrado en un teatro). Al parecer, el film alternaba espacios exteriores con una locación teatral. Como menciona Pritchard (2001), la posición de la cámara en el teatro permite observar los "diseños caleidoscópicos del suelo" tan importantes para el ballet (110). Del mismo modo, ayuda a comprender el carácter monumental de la obra al poder apreciar, especialmente en la danza "Il Risorgimento" del segundo cuadro, los espacios escénicos superpoblados en sus múltiples niveles, en los que participaba todo el cuerpo de baile.

Si en la primera mitad del ballet encontramos que se hace foco en individuos concretos, en la segunda lo que tendrá mayor peso son los logros colectivos, las grandes construcciones de ingeniería, como el Canal de Suez y el túnel del Monte Cenis. Eso no significa que en el ballet no se realice un reconocimiento a Ferdinand de Lesseps, por ejemplo, quien tuvo a su cargo la construcción del Canal de Suez (y el Canal de Panamá, que no concluyó). Puede observarse en el libreto que la última danza del séptimo cuadro es en su homenaje. En ese sentido, los cuadros finales portan la tesis de Excelsior, condensan el sentido promisorio del ballet: los progresos en la ciencia, la técnica y la industria llevarán a la fraternidad de las naciones.

En la escena de la excavación del túnel del Monte Cenis, los mineros e ingenieros italianos se encuentran, en las entrañas de la tierra [viscere della terra], con sus pares franceses (que excavaban también en la oscuridad, en sentido contrario). Se derriba 
la última roca que los separa y la Luz ingresa al túnel: "Tutto è trionfo" (cuadro IX, p. 19). En la gran escena final, apoteótica, se danza la "Quadriglia allegorico-fantastica delle Nazioni" y el ballet finaliza con niños sentados sosteniendo banderas formando la palabra "PAX" (Adamo, 2014: 152). Así, el optimismo en el progreso y la fe en la ciencia se sellan en una alegoría de la hermandad de los pueblos del mundo.

Como señala George Dorris, teniendo en cuenta la cantidad de cuadros que implicaban cambios de decorados, y todo lo que el ballet contenía, es destacable mencionar que duraba menos de ochenta y cinco minutos (2000:331). Dorris, además, menciona que

El diseñador Alfredo Edel completó el equipo que hizo tal éxito de Excelsior, con cientos de vestuarios elaborados y escenarios espectaculares como un desierto egipcio que se transformaba en un sitio festivo, un túnel de montaña, y un escenario de varios niveles para los grandes números alegóricos. (2000: 331)

["The designer Alfredo Edel completed the team that made Excelsior such a success, with hundreds of elaborate costumes and spectacular sets such as an Egyptian desert that turns into a festive site, a mountain tunnel, and a multitiered stage for the big allegorical numbers".]

Este derroche visual de los vestuarios, grandes decorados y mecanismos escénicos, y la dinámica del ballet dada en la sucesión de los cuadros, invitan a pensar, como Sergia Adamo ha planteado, no sólo el culto al positivismo y a la ciencia en los contenidos del ballet, sino además la estructuración de una forma de ver espectacular en sintonía con la construcción de la mirada en las Exposiciones Universales: "El Ballo Excelsior [...]representa la celebración del progreso y la dominación tecnológica del mundo a través de una estructura hecha de diferentes marcos que reproducen fielmente los itinerarios de las grandes exposiciones" (2014: 144) ["[..] Excelsior [...], depicts the celebration of progress and technological domination of the world through a structure made of different frames that faithfully reproduce the itineraries of the great exhibitions"].

Recordemos que las Exposiciones Universales de la segunda mitad del siglo XIX fueron también una forma de manifestar el poder y la expansión imperial de las naciones europeas al reunir en un mismo espacio no sólo las bellas artes, los avances de la ciencia y la técnica de distintos países, sino además artefactos culturales objeto de la curiosidad europea. Como menciona Julia Morillo Morales, las exposiciones universales "se convirtieron en pequeños universos o mundos de bolsillo [...] de modo que pasear por ellas era como dar la vuelta al mundo sin moverse del recinto de la exposición, conocer los nuevos productos, los nuevos avances técnicos y sus increíbles utilidades" (2015: 38). En palabras de Walter Benjamin, las exposiciones universales fueron "los lugares de peregrinación hacia el fetiche" (2005: 41), que inauguraban "una fantasmagoría" en la que penetraba el hombre "para hacerse distraer" (2005: 42).

En ese sentido, Excelsior podría pensarse en términos de un itinerario internacional fantasmagórico que exhibía el progreso del mundo occidental en la sucesión de sus cuadros, fetichizando los inventos, con la Luz como guía en ese camino único y lineal de la Historia. A su vez, el arsenal visual puesto en funcionamiento daba cuenta de un "paradigma exhibicionario de espectacularización" mayor (Adamo) [En inglés, la palabra exhibitionary no existe, por eso no tradujimos exhibitionary order como "orden exhibicionista"] mayor, y en el cual el ballet y las grandes exhibiciones nacionales e internacionales se encontraban insertos (como así también los museos, parques zoológicos, etc.):

[Excelsior] puede verse como una reproducción [...] de las muchas tensiones e impulsos que caracterizaron las exhibiciones mundiales en general: la cons- 


\begin{abstract}
trucción de una identidad nacional fundada en la exhibición de los dictados del progreso, lo inevitable confrontación con la otredad (interesante a este respecto la inserción de "bailes exóticos" y escenas orientalistas), la configuración de una dimensión 'mundial' o 'global' vista como una articulación de espacios nacionales únicos, [...] el entrelazamiento de diferentes discursos culturales en un espacio de espectacularización [...] (Adamo, 2014: 144)
\end{abstract}

["It can really be seen as a reproduction [...] of the many tensions and drives that characterized world exhibitions in general: the construction of a national identity founded on a showing off of the dictates of progress, the unavoidable confrontation with otherness (interesting to this regard the insertion of "exotic dances" and orientalist scenes), the configuration of a 'world' or 'global' dimension seen as an articulation of single national spaces [...], the intertwining of different cultural discourses in a space of spectacularization [...]" ]

En ese sentido, queremos destacar ese paradigma de espectacularización en el aspecto global de su circulación internacional. Si tenemos en cuenta, por ejemplo, que desde el 1 de septiembre hasta el 30 de noviembre de 1883 se presenta por primera vez Excelsior en Madrid (Gómez Cifuentes, 2019: 138), su simultaneidad con el estreno en Buenos Aires (que realiza funciones entre el 6 de septiembre y el 28 de octubre) no puede ser menos que llamativa: ¿había más de una compañía italiana girando por el mundo y escenificando este grandioso espectáculo?

En Madrid se había estrenado con la dirección de Manzotti "acompañado por el coreógrafo Carlo Coppi" y los papeles principales fueron interpretados por Giovannina Limido, María Cipriani y Antonio Monti (ninguno de los cuales aparecía mencionados en, por ejemplo, Buenos Aires en 1883. Por el contrario, "la Limido" era mencionada en una crítica del periódico El Mosquito el 7 de agosto de 1886 en referencia a la presentación de Excelsior en el viejo Teatro Colón ese año). Con respecto a su presentación en Nueva York, una pequeña mención en el The Brooklyn Daily Eagle (1883, 6 de octubre) en la sección "Dramatic and Musical" decía que "Excelsior' is playing to enormous business at Niblo's" y anticipaba que el maravilloso espectáculo no se vería en Brooklyn, sino hasta el año siguiente. La fecha, nuevamente, da cuenta (al menos) de una triple simultaneidad. Unos meses antes, el mismo periódico había comentado el inicio de la temporada teatral en Nueva York (se deduce que el estreno fue la noche del martes 21 de agosto en el Niblo's Garden) y brindaba otro dato: "los Kiralfys [Imre y Bolossy Kiralfy] han descartado a las antiguas matronas que durante tantos años han bailado para ellos, e importaron a doscientas bailarinas de ballet españolas y francesas, recién llegadas del viaje oceánico y agradables, placenteras y agraciadas" (Anónimo, 1883, 26 de agosto: s/p. ["The Kiralfys have discarded the ancient matrons who for so many years have danced for them, and imported 200 Spanish and French ballet girls, who are fresh from the ocean voyage and are agreeable, pleasing and graceful"]). Inclusive Bolossy Kiralfy, uno de estos hermanos empresarios, es llamado el "gran importador de bailarines de ballet" en Queen Bee (Anónimo, 1883, 5 de diciembre: s/p). Cuando los hermanos Kiralfy llevan Excelsior a Brooklyn, "producida igual" que en el Niblo's Garden de Broadway, señalan tanto el "espectacular triunfo" allí obtenido (188 funciones y cerca de 350.000 espectadores) como a las compañías europeas importadas: la Compañía de Ballet del Éden-Théâtre, la Troup de Ballet Veneciana y "los más distinguidos artistas del Teatro alla Scala de Milán". Quien reproduce el ballet en Brooklyn, en tres actos y con más de trescientos performers en escena, es Éttore Coppini.

En Río de Janeiro, Excelsior se estrenó el 4 de julio en el Imperial Theatro Dom Pedro II (Anónimo, 1883, 4 de julio: 2) y fue gestionado, como en Buenos Aires, por la empresa de Angelo Ferrari. En esta versión, la estructura era en tres partes y once cuadros. 
Con esto podemos observar, como menciona Adamo (2014), que indudablemente Excelsior era considerada por Manzotti como un modelo para ser reproducido. En la difusión mundial del ballet, Manzotti no podía supervisar cada una de todas las puestas en escena, y por esa razón había designado algunos repetitori autorizzati (repetidores o reproductores autorizados) para llevar adelante la tarea (2014: 159), como Carlo Coppi en Madrid, Éttore Coppini en Nueva York y Raffaele Grassi, "quien lo llevó a los escenarios de Río de Janeiro y Buenos Aires" (Gómez Cifuentes, 2019: 148), entre otros.

Solo para nombrar algunas modificaciones del ballet en su circulación internacional, podemos señalar que, en París, a los cien años de la Revolución Francesa (1889), la escena final se situó frente a la Torre Eiffel, y en 1905 en el Lyceum Theatre de Londres, el puente de Brooklyn fue reemplazado por el puente de Charing Cross (Pritchard, 2001: 114). En 1908, para la reposición de Excelsior en el Teatro alla Scala (dirigida por Caramba), el cuadro sexto del telégrafo eléctrico fue reemplazado por uno que celebraba la electricidad en general, con sesenta y cuatro bailarinas que representaban el telégrafo, el teléfono, la luz eléctrica y las chispas (Dorris, 2000: 331).

\section{La Argentina entre 1880-1916}

El período 1880-1916 en la Argentina se asocia, frecuentemente, con el período más exitoso de la historia económica del país. Como señala Fernando Rocchi, en esa etapa "la economía argentina experimentó un crecimiento tal que la llevó desde una posición marginal a convertirse en una promesa destinada a ocupar en América del Sur el lugar que los Estados Unidos tenían en América del Norte" (2000: 19).

La realidad, menciona Rocchi, parecía demostrar ese porvenir glorioso que le esperaba a la nación: si en 1881 las exportaciones habían sido de 11,6 millones de libras, para 1916 eran de 99,4 millones. Es decir, se habían multiplicado casi por nueve. Si los ferrocarriles para 1881 tenían una extensión de 2.442 kilómetros, para 1916 habían alcanzado los 34.534 kilómetros (20).

El crecimiento económico tenía como motor la exportación de productos primarios. Ya desde la segunda mitad del siglo XIX las ventas de lana al exterior habían crecido sostenidamente y habían convertido a ese producto en el bien exportable principal del país. Hacia fines del siglo, comenzó a diversificarse la estructura de las exportaciones con nuevas mercancías producidas para vender el exterior como el lino, la carne congelada ovina, los cereales, y los animales en pie. (19-20)

Para el Centenario de la Revolución de Mayo, la Argentina se había convertido en el tercer exportador mundial de trigo (después de Rusia y los Estados Unidos). Este lugar promisorio del país, casi indubitable, estuvo sintetizado en la caracterización de la Argentina como "granero del mundo". La revista Carasy Caretas publicaba, bajo el título "Argentina, el granero del mundo", lo siguiente (se respeta ortografía original): "año por año constatamos satisfechos cómo se eleva la cifra de nuestra exportación de cereales, que cual reguero de riqueza nos va elevando á un puesto prominente en el concierto de las naciones; año por año observamos orgullosos cómo el sobrante que enviamos al extranjero va conquistando para nuestra tierra fecunda el título valioso de granero del mundo" (Antuña, 1906, 28 de abril: 56).

Sin embargo, este lugar promisorio tenía su contracara o, más bien, su techo. Como señala el economista argentino Horacio Ciafardini, la Argentina ingresa de lleno al mercado mundial en la segunda mitad del siglo XIX, pero lo hace con la modalidad de una extrema especialización convirtiéndose "en mera exportadora de materias primas y alimentos" (1990: 30). Esta modalidad se explica al menos por dos razones articuladas: la primera, 
es que Inglaterra, en ese momento, tenía el desarrollo industrial más avanzado y no sólo necesitaba mercados para vender sus productos, sino fundamentalmente abastecerse de materias primas. En ese sentido, Inglaterra "se convirtió en poco tiempo en el polo dominante de una relación que tendría en el otro polo a la economía argentina agroexportadora, subordinada, dominada y especializada en extremo" (31). La segunda, que los grandes terratenientes (los dueños de la tierra, que configuran la clase social más poderosa del país y que se autoproclaman como fundadores del Estado nacional moderno) constituyeron el elemento interno que hacía posible esa "complementariedad subordinada" (32). A mayor industrialización de Inglaterra, mayor producción agrícola de Argentina, y menor posibilidad de una industrialización fuerte en el país.

La conquista de tierras para la explotación agraria capitalista fue uno de los métodos de la llamada acumulación originaria (Marx). En América, las campañas al desierto especialmente durante el siglo XIX no harán más que acrecentar la expropiación de los territorios de los pueblos originarios, mediante una violencia feroz. Ya desde la segunda mitad del siglo XIX, el alambrado fue la base del proceso de institucionalización del amparo a la propiedad terrateniente o, como dice Agustín Cueva, "la conformación definitiva de la propiedad capitalista del suelo" (1977:74) que permitió, al consolidar los derechos jurídicos, elevar la rentabilidad de la estancia, permitir aprovechar de manera más racional la tierra y disminuir la necesidad de mano obra para la vigilancia (Aldo Ferrer, en Cueva 1977: 74). Se trató de un monopolio del suelo por parte de las clases dominantes, a partir de la acumulación de tierras. Ahora bien, la lógica que imperó en la oligarquía terrateniente argentina no fue, podríamos decir, capitalista, sino más bien aristocrática. En el sentido de que esta no reinvertía sus ganancias en la producción, sino más bien que derrochaba. La lógica, como se dice, era la de la renta, no una lógica productiva. Como menciona Cueva, "la burguesía nace aquí confundida y entrelazada en su origen y su estructura con la aristocracia terrateniente" (1977: 85). No es casual, por lo tanto, que ese derroche se encuentre expresado, por ejemplo, en las suntuosas mansiones afrancesadas (los llamados hôtels particuliers) de la ciudad de Buenos Aires: como el palacio Ortiz Basualdo (1904), el Fernández Anchorena (1909), el Errázuriz (1911), el Paz (1914), entre otros.

Esa lógica aristocrática se convirtió en un serio obstáculo para el desarrollo industrial, inclusive cuando, a partir de la crisis económica mundial de 1929, las condiciones económicas para el desarrollo exigían un cambio radical de la estructura económicoproductiva. El llamado proceso de sustitución de importaciones a partir de la crisis -aunque está fuera de nuestro período estudiado-, señala esta distorsión. Llevar a cabo la industrialización por esta vía "sin desarrollar un sector productor de bienes de producción, implica ya una grave deformación del aparato productivo interno" (Cueva, 1977:95) [subrayado en el original].

Esta modalidad de extrema especialización y subordinación en el mercado mundial, en el capitalismo imperialista, es perfectamente extensible a los países de la región. Con esto lo que queremos señalar es simplemente cómo América Latina en el período que estamos trabajando fue terminando de constituirse en una región subordinada en el mercado internacional, la que se perpetuará hasta el día de hoy. Entre 1880 y la Primera Guerra Mundial "el capital imperialista controla los puntos nodales de la economía moderna de América Latina: ferrocarriles, minas, frigoríficos, silos de cereales, ingenios de azúcar, plantaciones y aparato financiero" (Cueva, 1977: 97).

Desde nuestra perspectiva, esta relación subordinada de Argentina en el mercado mundial intentará invisibilizarse en el plano cultural como así también en otros discursos vinculados al éxito económico argentino del período, al postular una sincronía ficticia con las potencias europeas. Excelsior, justamente, puede pensarse como un ballet al servicio de esta postulación. 


\section{Excelsior en el Teatro Colón en la ciudad efímera: un espectáculo para ser visto}

El jueves 6 de septiembre de 1883 a las 20:30 hs. se estrenó Excelsior en el antiguo Teatro Colón, ubicado frente a la Plaza de Mayo (Rivadavia y Reconquista, actualmente sede del Banco Nación). Para comprender mejor el contexto local, es preciso dar cuenta brevemente de lo que significó el primitivo Teatro Colón y el tipo de ciudad que era Buenos Aires en ese momento. El acto de inauguración oficial de este edificio el 25 de abril de 1857, con la ópera La Traviata de Verdi, fue considerado un "acontecimiento trascendental para el arte y la cultura argentinos" (Sala, 1969:35). No solo significó un cambio en la ciudad de Buenos Aires al incluir un nuevo espacio destinado a la música lírica en el mapa cultural de entonces, sino además por las características del proyecto arquitectónico del edificio. Los planos de este gran coliseo fueron confeccionados por el ingeniero Pellegrini y en la construcción se empleó, por vez primera en el país, armazones y tirantería de hierro (provenientes de los talleres Turner de Dublin). La sala contaba con una capacidad de 2500 personas, un escenario de doce metros de luz que lo establecía como el más amplio hasta el momento en Argentina, y estaba equipado para realizar grandes efectos escenográficos. Fue el primer teatro en utilizar luz de gas, lo que hacía que el encendido de la araña central de 450 lámparas, llamada La Lucerna, constituyera un espectáculo en sí mismo (Sala, 1969: 28). En una publicación de la revista La Máscara del año 1950, aparecía una evocación de esa noche:

Desde allí, desde la araña, pendiendo del techo poblado de cariátides, la potencia luminosa del gas anunciaba a los porteños en esa noche maravillosa la posibilidad del nuevo alumbrado a gas que pronto reemplazaría el de velas usadas en esa época. Y se levantó el magnífico telón entre los acordes del Himno Nacional [...] Esa noche Buenos Aires había crecido. Se despedía a la vieja aldea, recibiéndose a la ciudad en una fiesta espiritual del arte. (en Sala, 1969: 35)

Más allá de los tintes emotivos de un texto publicado casi un siglo después de ese acto inaugural, esta idea de dejar atrás la vieja aldea es un punto a tener en cuenta para pensar la ciudad de ese momento. Según Jorge F. Liernur, la metáfora de la Gran Aldea (ciudad de casas bajas blanqueadas a la cal, con su fuerte, su río, su cabildo, sus quintas y sus iglesias) y la de la metrópoli moderna del Centenario (ciudad de mansiones lujosas afrancesadas, de la Avenida de Mayo, el nuevo Teatro Colón, los faroles, el empedrado, el puerto y los conventillos) son de las pocas representaciones que se cuentan para pensar la ciudad de Buenos Aires de la segunda mitad del siglo XIX (1992: 103). Sin embargo, señala, habría una provisoria, la ciudad efímera. Entiende por ella a una ciudad que no ha quedado registrada en los grandes relatos de la ciudad, ni es "la Buenos Aires italianizante de Mitre y Avellaneda", del Colón de Pellegrini, de la aduana de Taylor, del Club del Progreso, la de los primeros inmigrantes "apiñados en las viejas casonas de San Telmo" (103). Es decir, que Excelsior se estrena también en esa ciudad, cuya transitoriedad de sus construcciones entre la Batalla de Caseros y la crisis de 1890 parece expresar una "incertidumbre generalizada, el estadio anterior al de un proyecto consolidado, un tiempo sin utopía compartida" (107). Liernur entiende que la presencia de la ciudad efímera (aunque tramada con restos pasados y atisbos futuros de las ciudades sólidas de las tres metáforas mencionadas más arriba)

es lo suficientemente importante como para permitirnos comprender que fue este ambiente mayoritariamente "provisorio", el que configuró el marco urbano que debió habitar la "generación del "8o" mientras soñaba y estaba construyendo la ciudad del Centenario. Quizás por esa ley de dislepsia [sic] entre los fenómenos económico-políticos y los culturales, la "ciudad de la oligarquía" parece más bien un producto del siglo XX [...] (117) 
Excelsior es traído al país en 1883 por el empresario de ópera italiano, residente en Argentina, Angelo Ferrari. Este empresario se había hecho cargo del teatro con bastante éxito desde el año 1868, logrando mantener, según Juan Andrés Sala, el más alto nivel artístico (1969: 42). Según Tulio Halperín Donghi, Buenos Aires, luego de la caída de Rosas "volvía a gozar de alguna prosperidad", se construyeron teatros y se pavimentaron calles. "Por otra parte, hay un conjunto de progresos técnicos que irrumpen para cambiar el aspecto de las ciudades: el gas en la década del cincuenta reemplaza al aceite y a la maloliente grasa vacuna o equina como medio de iluminación en Buenos Aires, en Valparaíso, en Lima, después de haberse impuesto en Río de Janeiro. Al mismo tiempo los nuevos medios de transporte [como el vapor] acercan a las ciudades de Europa [...] Esas oportunidades nuevas son utilizadas con entusiasmo: los nuevos teatros se pueblan, gracias a los nuevos vapores, de compañías de ópera italianas, primero deplorables, que mejoran rápidamente cuando se descubren las posibilidades de lucro que ofrece un público inculto pero generoso" (2005: 212). Como menciona Pasolini, las causas locales de la hegemonía de la ópera italiana se fundaban tanto en la oferta de las compañías y el origen italiano de los empresarios que, como Ferrari, explotaban los teatros, como así también en la presencia de un público diletante italiano que buscaba un lugar en la elite argentina (1999: 228).

Con el debut de "la gran Compañía Coreográfica Italiana" -así presentada en los diarios de la época- el ballo grande de Manzotti y Marenco pisaba suelo rioplatense. En la sección "Teatros" de La Tribuna Nacional (Anónimo, 1883, 5 de septiembre: s/p) se publicitaba la obra del siguiente modo:

COLON - Empresa A. Ferrari - Debut de la gran Compañia Coreográfica Italiana - Juéves 6 de Setiembre de 1883, primera representacion de la grande accion coreográfica dividida en tres partes y doce cuadros, EXCELSIOR -composicion de Luis Manzotti, reproducida por el coreógrafo y 1er bailarin Sr. Raffette Grassi, música del maestro Romualdo Marenco - Primera pareja: Sra. Emma Bessone, Sr. Raffette Grassi.

\section{PERSONAJES}

La Luz, Sra. Jany de Sovino

El Oscurantismo, J. F. Magri

La Civilizacion, L. E. Bessone

Valentin Barneso, R. Grassi

Un esclavo, ídem

Pajin, S. Pedoni

Rico señor árabe, ídem

1er. ingeniero italiano, Franché

Volta, G. Saracco

Mercado de esclavos, ídem

$2^{\circ}$ ingeniero italiano, Gualde

Fritz basqueso, ídem

Un chino, id
Mejicano, L. A. Sezaggi

Jefe minador italiano, ídem

Gmo. Colono, Pianamide

Un señor turco, Giaghini

Ing. Francés, Piantauride.

Un inglés, C. Bansi.

Jefe de los eunucos, Pmide.

Fany nóvia de Vtin. E. Crotte

Hija del mercader árabe, Arn.

Cuniguada esposa de Jorge.

Madre Asaba, Mancor.

Una joven alemana, E. Grasi.

Génios de la Civilizacion - de la Constancia - de la Inventiva - de la Concordia de la Fama - de la Fuerza - de la Gloria - de la Ciencia - de la Agricultura - de la Industria - del Valor - de la Union - Banqueros - Aldeanos - Músicos - Postilbacs - Portadores de despachos telegráficos - Ingenieros - Minadores - Operarios de las minas europeas - Africanos - Asiáticos - Americanos - Marinos - Oficiales Banda de música - Corifeos á caballo, etc. - A las 8 1/2. 
Tanto en esta, como en otras citas de años subsiguientes, se ha respetado la ortografía y/o los errores de imprenta del original. Para poner solo un ejemplo, el nombre de quien interpreta el personaje de la Luz está mal escrito. El diario El Mosquito, mencionaba no a Jany de Sovino, sino a Fanny de Torino (Doré, 1883, 16 de septiembre: 3). Sin embargo, Honorio Destaville (2008) señala que se trataba de una gran mima, Fanny de Sovino, y que erróneamente se la recordaba, por un error de los cronistas, como Fanny Lovino (23).

Podemos decir algunas cuestiones en relación con esto. En primer lugar, que aparece ya una modificación en la estructura: no son once sino doce cuadros. Según pudimos observar en el libreto francés de Excelsior para el Éden-Théâtre impreso en 1882, allí la estructura de las seis partes se mantiene, pero se incorpora un cuadro más al final, llamado "Apothéose de la Lumière et de la Paix". También se realizaron otras modificaciones y suplantaciones: se agregó una danza en el séptimo cuadro, luego de "La Indiana", titulado "Abolition de l'Esclavage" y se reemplazó el décimo cuadro "Oscuridad, Luz y Gloria" por uno llamado "Le grand Français". Tampoco en seis partes, sino en tres, como en Brasil. En segundo lugar, se aclara que se trata de una representación de Manzotti, pero reproducida por el coreógrafo y primer bailarín Raffette Grassi, lo que confirma lo señalado más arriba.

Excelsior realizó en Buenos Aires treinta y una funciones con bastante éxito. Ya el diario La Prensa, el día anterior al estreno, publicaba un comentario sobre el ensayo de la noche del 5 de septiembre en el que mencionaba que las localidades para el estreno estaban agotadas y que quedaban pocas para la segunda función (recordemos que la sala tenía una capacidad de dos mil quinientas personas). El cronista, además, no dejaba de expresar su entusiasmo por lo que había visto. Justamente, la visión es el eje común de varias críticas del momento, lo que enfatiza la novedad espectacular del ballet:

Mas que ensayo puédese llamar representacion del baile de Manzotti, la que tuvo lugar anoche.

El teatro, iluminado y concurrido casi como en sus mejores noches, ofrecía un hermoso golpe de vista.

[...]

Razon tenian en Francia cuando, despues de la representacion del "Excelsior", decian que, despues de este, ningun baile podría representarse ya, pues todos serian pálidos á su lado.

Efectivamente, el "Excelsior" es algo de monumental [...]

Esta accion coreográfica, es un variado kaleidoscopio, en el cual desfilan, sucesiva y fantásticamente representadas, todas las mas bellas creaciones del génio humano. [...]

El primer cuadro representa la luz sumida en el fondo de una lóbrega cárcel y cargada de cadenas, mientras que impera el oscurantismo y á lo léjos se divisa una ciudad en ruinas.

De pronto cambia la escena y aparecen la luz y la civilizacion en un palacio replandeciente, morada del Génio y de la Ciencia.

En este cuadro maravilloso se suceden las mas bellas combinaciones escénicas en que centenares de personas con lujosos trajes, combinados hábilmente los contrastes de los diferentes matices, llegan á producir un efecto que hace involuntariamente pensar en las mil y una noches.

Estos cuadros no son para ser descritos sino vistos y admirados de visu. [...] (Mefistófeles, 1883, 6 de septiembre: $\mathrm{s} / \mathrm{p}$ )

Al día siguiente del estreno, el diario El Nacional comentaba la primera noche del ballet y comprendía el "entusiasmo de lo pálidos habitantes del opulento Imperio de los trópicos": 
[...]Excelsior es la más lujosa y brillante exposición de las decoraciones teatrales combinadas con la danza.

La escenografía y la coreografía han desplegado en Excelsior sus mayores esplendores. (Anónimo, 1883, 7 de septiembre: s/p)

Y, en otro apartado de la misma nota, firmada por coreógrafo (¿seudónimo del cronista, o palabras traducidas de Manzotti, o de uno de sus repetitori autorizzati?), decía:

El Excelsior es un espectáculo que ríe, canta y embelesa el ojo del espectador ávido siempre de impresiones que lo seduzcan con todas las galas de una fantasía exuberante.

Así tenemos que el auditorio se paraliza cuando ve desfilar en el mas movible de los espectáculos, tules que ondean por los aires, colores que se confunden, grupos que encantan y músicas que arrullan al oído y adormecen lánguido al espíritu. [...] [...]Excelsior es un espectáculo espléndido para la vista. (s/p)

Meses antes al estreno en Buenos Aires, en Río de Janeiro, una de las primeras críticas del espectáculo señalaba aquel momento de cambio de decorado entre los dos primeros cuadros del ballet (aquél que se puede observar en el film de Comerio citado anteriormente), y el impacto producido:

El efecto de la mutación en ese punto es realmente deslumbrante. Como por encanto, desaparecen las ruinas que llenaron la escena, y esta, súbitamente iluminada a luz eléctrica, ofrece una vista brillante, llena de figuras soberbiamente vestidas y que en grupos artísticamente dispuestos ocupan todo el teatro hasta el plano superior del fondo. (Anónimo, 1883, 6 de julio: 2)

[En el original (se respeta ortografía original): "O effeito da mutação n'esse ponto é verdadeiramente deslumbrante. Como por encanto, desapparecem as ruinas que enchiam a scena, e esta, subitamente iluminada á luz electrica, oferece uma vista brilhante, cheia de figuras soberbamente vestidas e que em grupos artisticamente dispostos occupam todo o palco até o plano superior do fundo".]

Pasar casi al instante de una escena lúgubre, oscura, a un decorado repleto de cientos de performers que acapara todo el campo visual, debe haber producido en el público un asombro generalizado, también en Buenos Aires. Es que no sólo la luz y la oscuridad aparecían como personajes alegóricos, sino que en términos formales fueron recursos técnicos sumamente importantes para producir efectos de choque, en función también de la dinámica en la sucesión de los cuadros. Si bien en la cita de la première en Río de Janeiro se menciona la luz eléctrica, cuando se entrenó en Milán la luz eléctrica no era usada en los teatros, como seguramente tampoco en 1883 era usada en el Teatro Colón. Por el contrario, en Nueva York, los hermanos Kiralfy se contactaron con Thomas Edison para incorporar la bombilla incandescente al espectáculo, en función de acrecentar los efectos visuales de Excelsior y publicitar los nuevos avances científicos (Postlewait, 1999:127-128). De ese modo,

Edison y los hermanos Kiralfy diseñaron una producción final que fue iluminada brillantemente por más de quinientas bombitas de luz, que se adhirieron a los vestuarios de docenas de bailarinas y a la escena, una representación del nuevo Puente de Brooklyn. A cada corista también se le dio una varita eléctrica con una lamparita en la punta. Edison colocó baterías en los corsés de los disfraces, e instaló su dínamo de cincuenta y cinco voltios en el teatro con el fin de generar la energía para llevar a cabo los "efectos de iluminación novedosos", como decía el programa [...] (129) 


\begin{abstract}
["Edison and the Kiralfy brothers designed a production finale that was brilliantly illuminated by more than five hundred light bulbs, which were attached to the costumes of dozens of dancers and to the scenery, a representation of the new Brooklyn Bridge. Each chorus girl was also given an electric wand with a small bulb at the tip. Edison placed batteries in the corsets of the costumes, and he installed his fifty-five-volt dynamo in the theatre to generate the power to run the "novel lighting effects," as the theatre program stated [...]".]
\end{abstract}

En Buenos Aires, la lámpara incandescente de Swan-Edison se había conocido un par de años antes, entre 1878 y 1881 (Liernur y Silvestri, 1993: 11), pero su uso para la escena sería posterior. Aún la ciudad se iluminaba con faroles a gas y kerosene. Según la publicación de la Compañía Alemana Transatlántica de Electricidad con motivo del Centenario de la Revolución de Mayo en 1910, el Teatro Ópera, reinaugurado en 1889 (su primera inauguración había sido el 25 de mayo de 1872), fue el primer teatro en América Latina "con una iluminación completa de iluminación eléctrica y con exclusión absoluta de alumbrado á gas" (1910: 11).

La luz eléctrica era el paradigma del proceso de modernización, pero en el momento que se estrena Excelsior recién había comenzado a aparecer como proyecto de iluminación de la ciudad de Buenos Aires (Liernur y Silvestri, 1993: 27). Es entre 1882 y 1885 cuando se da el primer período de electrificación (por supuesto, se trataba de instalaciones precarias). Liernur y Silvestri destacan que "el empleo de electricidad para la iluminación de la ciudad de Buenos Aires se produjo con relativo retraso" y que el gas como fuente de energía para iluminar la ciudad "subsistió hasta bien entrado el siglo XX" (20). Solo pequeños y eléctricos destellos, podríamos decir, comenzaban a aparecer en la noche de la ciudad efimera. Cuando Excelsior se presenta en 1886 en el Teatro Colón, un comentario en el diario El Mosquito del 8 de agosto de ese año lo comparaba con Brahma, diciendo que este último era más pobre comparado con aquél: "tiene el brillo de una vela al lado de la luz eléctrica". La referencia a la electricidad no es casual, ya que se trataba de una novedad, causaba asombro. En la misma sección del periódico en la que se publicitaba Excelsior, también se anunciaba: "GRAN PANORAMA DE BUENOS AIRES. Plaza General San Martin - Gran rebaja de precios -Entrada de dia y noche 50 centavos - Luz eléctrica - Efecto sorprendente".

\title{
Excelsior y el dilema argentino
}

¿Cuál era el contexto del espectador de Excelsior en 1883? ¿Qué temas trataba el ballet que podrían haber resonado en los espectadores del Teatro Colón de entonces?

El séptimo cuadro de Excelsior, "El Simún", sucede en el desierto, donde "el ojo se pierde en un horizonte sin fin" ["L'occhio si perde in uno sterminato orizzonte".] (Manzotti y Marenco, 1881: 15). Es, básicamente, un "terrible cuadro de desolacion [sic]" (Mefistófeles, 1883,6 de septiembre: $\mathrm{s} / \mathrm{p}$ ). En el desierto, cuando se acerca la tormenta de arena, una caravana es atacada por una manada de ladrones a caballo, y para cuando la tormenta llega todo es caos, confusión y oscuridad. Según el libreto: "la arena produce una espesa oscuridad, cielo y tierra parecen unidos" ["la sabbia produce una fitta tenebra, cielo e terra sembran congiunti insieme".] (Manzotti y Marenco, 1881:15). Es el cuadro donde triunfa el Oscurantismo: "la oscuridad va creciendo y oculta víctimas y desierto" ["L' oscurità va crescendo e cela vittime e deserto"] (16). Por supuesto, este cuadro sirve de contrapunto al siguiente (El Canal de Suez), donde en lugar del desierto se ve el canal en un bellissimo panorama. "Toda la civilización europea está reunida como por encanto en ese punto del istmo, anteriormente desierto" ["Tutta la civiltà europea è riunita come perincanto in quel punto dell' istmo, prima affatto deserto". El subrayado es mío] (16). Los pueblos no europeos parecen estar fuera de la civilización. Aunque aparezcan en escena son representados exóticamente. Como señala Adamo: 
el Ballo Excelsior puede ser considerado como algo más que una celebración ideológica del progreso tecnológico y el internacionalismo fine de siècle. Las intenciones explícitas de adoctrinamiento paternalista que el ballet repite obsesiva y didácticamente pueden también verse como un marco para la representación de la alteridad no-Occidental, la que es una parte constitutiva del ballet. (2014: 170)

["the Ballo Excelsior can be considered as something more than an ideological celebration of technological progress and fine de siècle internationalism. The explicit intentions of paternalistic indoctrination that the ballet obsessively and didactically repeats can also be seen as a frame for the representation of non-Western otherness, which is a constitutive part of the ballet".]

La lucha de la Luz contra la Oscuridad, del progreso contra el estancamiento y la decadencia, en el contexto de la Argentina de la segunda mitad del siglo XIX podía ponerse en los términos sarmientinos de Civilización/Barbarie.

Esta imagen, como estudia Maristella Svampa, recorre la literatura y el pensamiento latinoamericanos (2010:33). En la época de la constitución de los Estados nacionales en el siglo XIX que se realizó bajo la impronta de Europa y, también, de los Estados Unidos, los dilemas que presentaban las élites intelectuales de los diferentes países (republicalismo/catolicismo; democracia/absolutismo; civilización/barbarie) "recubrían bajo etiquetas diferentes un mismo proceso: el combate del progreso contra la reacción" (34). España, en ese entonces (como sería representado el personaje del Oscurantismo en Excelsior muchos años después), no podía ser ningún modelo, ya que, para las élites criollas del momento, encarnaba un medievalismo expresado tanto en el absolutismo como en la Inquisición: "El legado español parecía expresarse en el retraso, la anarquía, la contrarrevolución” (34).

Inglaterra, Francia y los Estados Unidos eran, fundamentalmente, los ejemplos a seguir. Este último país aparecía como aquel que había triunfado en su lucha contra la barbarie y establecido, por esa razón, el divorcio de las dos Américas. Sin embargo,

la imagen presentaba una gran eficacia simbólica, puesto que proporcionaba una historia común a ambas Américas; la lucha entre dos principios incompatibles restituía imaginariamente la unidad del continente, las acercaba en un punto nodal de su historia: el tránsito de la barbarie a la civilización” (38).

En ese sentido, a la unidad espacial se le superponía una linealidad cronológica progresiva a recorrer, con una única dirección: el futuro. Esta narrativa positivista es la que se manifiesta explícitamente en Excelsior y que a la vez que construye ese relato evolutivo, produce también su antagonista que hay que eliminar, destruir: la barbarie, el pasado, el atraso. En palabras de Svampa, "el pasado debía ser la América española e indígena, manifiesta en sus instituciones tiránicas, sus costumbres bárbaras y su desprecio por el progreso" (39).

En los mismos diarios que se comentaba sobre Excelsior, otras noticias y publicidades pintaban la realidad del país del momento. Tanto las largas columnas comentando sobre "Los tehuelches" y sus costumbres, los anuncios de los extendidos de las líneas férreas o los debates sobre un futuro parque zoológico, como las publicidades sobre máquinas para la agricultura y la industria, o sobre las líneas regulares en nuevos barcos de vapor de ida y vuelta con Europa, marcan distintas facetas de ese mismo trayecto de progreso y modernización, a la vez que exhiben sus caras más sombrías.

Realmente son "detalles interesantes" los que aparecen en el artículo sobre "Los Tehuelches" en el diario La Prensa al describir el acto reparador del gobierno: "la 
resolucion fué la que correspondia, disponiéndose que los indios fuesen restituidos á sus hogares, que se les devolviesen sus caballos, se les agasajase con regalos, se les vistiese y se les tratase bien y amistosamente" (Anónimo, 1883, 3 de agosto: s/p).

Cuando el Sr. Don Ramón Lista les informa a los tehuelches que "no habían venido como prisioneros sino como amigos" y que volverían a la Patagonia, los indios "entonaron un canto salvaje, monótono y lúgubre" (tres palabras que condensan el Regresso). El Sr. Lista "los embarcó en un tren expreso" hasta Retiro, y el cacique Orkeke dirigió a los indios "en su lengua diabólica" palabras que causaron, según la crónica, buena impresión. El texto continúa mencionando lo bien que fueron tratados los tehuelches en un intento de mostrar el lado civilizado a la opinión pública y que no hace más que confirmar la barbarie cometida contra esa etnia. Inclusive se anuncia que "El viejo boleador de la Patagonia" (el cacique Orkeke) será llevado a Palermo por el Sr. Lista, acompañado del Diplomático Dr. Escudero y del comandante Hort (nótese la taxonomía impuesta por las fórmulas de tratamiento), para recrearlo e "inspirarle la confianza del amigo y hacerle comprender que el Gobierno y los cristianos los aprecian en alto grado". Más tarde, se dice, el Sr. Lista "piensa llevar á Orkeke á una funcion de teatro". La crónica termina felicitando al gobierno, e informando que también comerciantes patagónicos, acusados de "ejercer comercio ilícito" con los tehuelches, fueron puestos en libertad. Aquí la postura paternalista hacia los tehuelches marca un giro, al defender la posición usurera de los comerciantes patagónicos: "¿quién ha nombrado al ejército y al Gobierno tutores de los indios? ¿Acaso la usura es un delito por nuestras leyes?". Hacia el final, se menciona que "esos comerciantes hacen, á pesar de todo, un gran servicio" y que "contribuyen á la civilizacion y amansamiento de los indios, como efecto natural de su roce con ellos; son unos verdaderos héroes" (Anónimo, 1883, 3 de agosto: s/p).

Que los tehuelches hayan llegado a Buenos Aires a bordo del "Villarino", que en otro momento los hayan llevado en un tren expreso y posteriormente al teatro, bien podría ser un cuadro de Excelsior. En este retrato de la situación que establece la crónica, podríamos decir con Marta Penhos que se acentúa "la imagen oficial de la campaña: no se trata de una guerra contra los indios sino de una campaña a favor de la civilización" (1995: 115). Por supuesto, los hechos desmienten la imagen oficial. Si el científico, como paradigma de la objetividad es un agente a favor de la civilización y no en contra de los indios, puede observarse su revés en la contundente frase de Zeballos (en una expedición en la que buscaba tumbas indígenas para exhumar restos con fines científicos): "la barbarie está maldita y no quedarán ni los despojos de sus muertos" (citado en Penhos, 2005: 26).

Creemos importante destacar aquí la consideración del ballet como un dispositivo coreográfico que forma parte de lo que Adamo llama el paradigma exhibicionario de espectacularización:

A través de este complejo y heterogéneo aparato, el Ballo Excelsior consiguió crear un sentido de experiencias compartidas a nivel global, proveyendo a la audiencia una autoimagen colectiva capaz de acomodar también la identidad nacional en su kitsch, fantasmagórica imaginación de un otro circunscrito y neutralizado. (Adamo, 2014: 172) [Through this complex and heterogeneous apparatus, the Ballo Excelsior managed to create a sense of shared experiences at a global level, providing the audience with a collective self-image able to accommodate also national identity in its kitsch, phantasmagoric imagination of a circumscribed and neutralized other".]

En ese sentido, la otredad representada en Excelsior funciona de manera intercambiable con cualquier otredad local, por la propia dinámica de construcción imaginaria de un nosotros civilizado/otros bárbaro. 
Otro de los inventos que pondera Excelsior es la locomotora, uno de los exponentes por antonomasia de la Revolución Industrial. Conforme avanzaba el ejército en la llamada "Conquista del Desierto", esparciendo las fronteras, expropiando tierras y aniquilando a los indígenas, se iban extendiendo las líneas del telégrafo y las vías del ferrocarril (Penhos, 1995: 118).

Cuatro meses después que se inauguraba el primitivo Teatro Colón, también se inauguraba la primera línea ferroviaria argentina, de diez kilómetros de extensión (Scalabrini Ortiz, 1975: 29). La estación se ubicaba donde, curiosamente, hoy se encuentra el nuevo Teatro Colón, en Plaza Lavalle. La primera locomotora a vapor del país, llamada "La Porteña", hizo el trayecto desde la Estación del Parque rumbo al oeste hasta Floresta. Como señala Scalabrini Ortiz, a medida que al correr del tiempo las vías se extendían hacia el oeste, los campos de Pearson, Dillon y Pellon, las estancias de Thomas Gahan, de Wyatt Smith, las tierras de Robert Kelly, Owen Lynch, John Brown, Peter Ham, etc. (nótense los nombres) se valorizaban enormemente por el ferrocarril (1975: 35). Para 1883, el Ferrocarril del Oeste tendrá una extensión de 583 kilómetros (52), lo que significaba ampliar la explotación económica de tales tierras.

El diario La Prensa, el día del estreno del ballet en un artículo llamado "El Ferro-Carril de Mar del Plata á Bahía Blanca", decía:

Estamos en la aurora de una nueva era de fecundo progreso para el pais, puesto que la competencia en materia de vias de comunicacion debe forzosamente atraer grandes beneficios á la comunidad, tanto por el estímulo que desarrollaráse entre las diversas compañias y el Estado, en provecho de mejor servicio, cuanto por el mayor acopio del mas fecundizador elemento de civilizacion, cual es un ferro-carril en comarcas despobladas. (Anónimo, 1883, 6 de septiembre: s/p)

Si en Excelsior se exaltaba los valores de los progresos técnicos que llevarían a una paz e igualdad de las naciones del mundo, el caso del ferrocarril en los países de América Latina era una de las herramientas por las cuales el imperio (fundamentalmente británico) estructuraba las relaciones de dependencia. Como menciona Scalabrini Ortiz,

Los pueblos que acercaba al tráfico internacional o los que creaba con su posibilidad de comercio iban quedando encadenados a la voluntad omnímoda de los mismos ferrocarriles. El ferrocarril engendraba pueblos con grilletes, y la malla ferroviaria se asentaba sobre los países nuevos para inmovilizarlos y ofrecerlos inermes a la codicia de los financieros que habían creado ese mismo ferrocarril (1975: 16).

Por el propio entramado de la red ferroviaria no se facilitaba, por ejemplo, el comercio interior: el destino era la exportación. Lo que señala Scalabrini Ortiz es interesante para pensar el contraste entre la representación universalizada del ferrocarril como invento de la humanidad, en el plano de lo imaginario, y las relaciones de dominación presentes en el plano de la realidad concreta, establecidas por ese mismo invento.

Si recordamos el final apoteótico del baile de las naciones, es revelador lo que mencionaban algunas de las críticas del espectáculo, entre ellas la siguiente de La Prensa:

El "Excelsior" produce aquel noble entusiasmo que despiertan los himnos patrióticos, y en verdad que es un himno y grandioso en sumo grado, pues canta las glorias de la mas grande de las pátrias: de la humanidad entera!

[...]

Ferrari ha tenido la delicada idea de hacer intercalar un arreglo de nuestro himno pátrio en la cuadrilla final de las naciones. 


\begin{abstract}
Esto, como es natural ayuda poderosamente pa dejar una grata impresion en los espectadores por el honroso puesto asignado á nuestra patria en el concierto de las naciones.

Estos son los apuntes que ligeramente y al correr de la pluma podemos consignar hoy acerca de la representacion de una obra que por mucho tiempo despertará el entusiasmo universal.

Desde ayer, no solamente estaban tomadas todas las localidades para la primera funcion, sinó que ya lo estaban también casi todas para la segunda.

Esto dá la medida de hasta que punto ha llegado entre nosotros el entusiasmo por la obra de Manzotti. (Mefistófeles, 1883, 6 de septiembre: s/p)
\end{abstract}

Estos párrafos son significativos, ya que señalan un modo de apropiación del modelo de Excelsior. Desde su estreno, y con la circulación mundial del ballet, hubo innumerables modificaciones a lo largo de los años. Seguramente la idea de Ferrari no haya sido original, ya que en otras versiones aparecen varias inclusiones vinculadas al país receptor. Sin embargo, más allá de eso (de si eran previstos ese tipo de arreglos a las escenificaciones del ballet) lo interesante es pensar la función de esa inclusión, más allá del espectáculo mismo. Una clave la da el uso del tiempo verbal manifestado en la crónica citada: el entusiasmo universal futuro que despertará Excelsior, se localiza en aquel que ya despertó en los espectadores del viejo Teatro Colón, construyendo así un nosotros temporal e ideológicamente sincrónico con las escenificaciones en otros países de importancia: en Argentina Excelsior ya pasó, por lo tanto, ahora el país lleva, o comparte, la delantera civilizatoria. Como se menciona en esos párrafos, esa inclusión dejaba una grata impresión por el honroso puesto asignado a la Argentina, esto es, al mismo nivel civilizatorio que los países europeos, invisibilizando de este modo la relación de dominación presente en el concierto real de las naciones.

\title{
La versión libre de Excelsior en el nuevo teatro Colón (1916)
}

Es indudable que Buenos Aires avanza á pasos agigantados. El París de América está cada día más orgulloso de marchar á la cabeza de la civilización.

Hasta saber que acuden anualmente las grandes notabilidades teatrales para demostrar con la mayor claridad que compartimos los gustos más refinados con el viejo mundo. (Anónimo, 1906, 28 de abril: 68).

La inauguración del nuevo Teatro Colón el 25 de mayo de 1908 significó, como la inauguración del primero en 1857 , todo un acontecimiento, especialmente para la alta cultura de la ciudad de Buenos Aires que vio en este teatro la manifestación oficial del arte culto.

Como menciona Pola Suárez Urtubey (1969), desde los inicios de la excavación en 1889 hasta su inauguración (la que originalmente debía ser para el cuarto centenario del descubrimiento de América) pasaron veinte años de interrupciones y frustraciones para concretar el deslumbrante proyecto que había ganado la licitación: el de Angelo Ferrari, preparado por el arquitecto Francisco Tamburini. La muerte marcará la sucesión de quienes eran los directores técnicos del proyecto: Tamburini, Víctor Meano (asesinado) y Julio Dormal, así como el pasaje del empresario Ferrari a la empresa constructora Pellizari e Italo Armellini.

Si bien el teatro se inauguró incompleto, ya que faltaban terminar algunas decoraciones importantes, la revista Carasy Caretas decía ese mismo día: "Buenos Aires tiene en él uno de los mejores teatros del mundo y podríamos decir que el mejor de todos, si lo consideramos en conjunto" (1908, 25 de mayo: 55); y más adelante: "la sala y el proscenio, por ejemplo, han sobrepujado las dimensiones del San Carlo de Nápoles y la Scala de Milán" (56). 
Que se mencionaran estos dos últimos teatros italianos no era casual, porque constituían los teatros de ópera por antonomasia. El viejo y el nuevo Colón habían sido pensados para ese género y, en el caso del último, podía ser considerado como una sucursal de la Scala: en las primeras temporadas, la mayoría de los componentes de coro, cuerpo de baile y orquesta era contratada en Italia, incluso los decorados pertenecían a la Scala (Caamaño, 1969: 117-118). El nuevo Teatro Colón era la manifestación de un proceso de refinamiento del gusto del público acorde a los estándares internacionales europeos. Para esa época, señala Ricardo Pasolini, "en términos de consumo y erudición, el público de Buenos Aires no se diferenciaba tanto de otros públicos del mundo moderno" (1999: 225).

Tanto el viejo como fundamentalmente el nuevo Teatro Colón se constituyeron en espacios de expresión de lo que podríamos llamar una performatividad de clase ociosa, de una serie de actos y ritos que ostentaban el rango aristocrático de las élites locales. Como mencionan Waldo Ansaldi y Verónica Giordano, “[...] la dominación oligárquica definió imaginarios sociales, representaciones y comportamientos colectivos, símbolos sintetizables en la expresión modo de ser oligárquico propios de ese locus de gestación privado" (2012: 477). Los rasgos de frivolidad, la ostentación de dinero, el encumbramiento de la raza blanca, el goce del ocio, el apellido, las relaciones de parentesco real (y simbólico) y la ponderación de las Artes eran algunos de los valores fundamentales de ese modo de ser (477).

Los palcos del nuevo Colón respondían a la modalidad francesa (es decir: con divisiones bajas entre uno y otro, completamente abiertos), y Víctor Meano explicaba del siguiente modo la decisión de hacerlos así en 1893: "de este modo los espectadores pueden ver y ser vistos" (en Rapallo 1969: 177). De esa manera, se ponían en juego distintas teatralidades (organizaciones de la mirada) al interior mismo del espacio arquitectónico.

La performatividad oligárquica era una forma de constituir una identidad culturalmente europea, sustentada en un proceso de diferenciación radical en relación con las otras clases sociales. En palabras de Pasolini, "en los primeros años de la década de 1880, la elite porteña apostó a una diferenciación extrema, donde el modelo a adoptar era el bon ton de las clases acomodadas europeas" (1999: 237). En ese sentido, el nuevo Teatro Colón vino a restablecer las antiguas jerarquías que, en los veinte años desde la clausura del viejo teatro Colón, se habían visto amenazadas tanto en el Teatro Nacional como en el Teatro de la Ópera (242).

Excelsior se estrenó en ese nuevo Teatro Colón el 15 de junio de 1916 y realizó allí doce funciones (compartiendo el programa con otras obras) hasta el 8 de agosto inclusive (Caamaño, 1969: 55, 347). Excelsior se presentó completa diez veces, junto con Il segreto de Susanna el 15, 18, 25 de junio. El 26 de junio con los actos I, II y III de Fausto; el 2 de julio con los actos I y II de Manon. El 7 de julio con otras obras y fragmentos de obras en un homenaje a Saint-Säens; el 10 de julio nuevamente con Il segreto de Susanna, con Huemac el 28 de julio y con I Pagliacci el 6 y el 8 de agosto. Los actos I y III de Excelsior se representaron junto a I Pagliacci el 3 de julio y con los actos I, II y III de Manon el 14 de julio.

El ballet se presentó en tres actos y doce cuadros, en la nueva versión de Renato Simoni y Caramba, con coreografía de Romeo Francioli. En esta ocasión, se anunciaban seiscientas personas en escena (Anónimo, 1916, 15 de junio: 4). El programa que disponemos no presenta mayor información respecto al argumento (nos referimos al programa de mano de Excelsior junto con I Pagliacci, disponible en la Biblioteca del Teatro Colón), pero los nombres de los personajes alegóricos y reales dan cuenta de ciertas variaciones a la versión modelo del ballet: si en la de 1883 los personajes 
alegóricos principales eran la Luz, el Oscurantismo y la Civilización, en esta versión los dos primeros serán reemplazados por la Justicia (interpretada por Sta. J. Rouban) y la Violencia (por Sr. Aug. Francoli), y si bien se mantendrá el personaje de la Civilización (por Sta. G. Anzzolini) se agregará otro: la Liga de los Pueblos (por Sta. Battaggi). De los Genios se mantendrán: los de la Civilización, de la Industria, de la Concordia. No aparecerán más los Genios de la Ciencia, de la Gloria, de la Fama, entre otros, y se incorporarán los Genios de la Marina y los del Derecho. Aparecerán Senadores romanos, oficiales, científicos, estudiantes, ministros, bárbaros y el líder de los bárbaros, un gran duque, un burgués, un holandés, un español, un norteamericano, un chino, una bailarina india.

Como menciona en su reseña George Pritchard, esta versión de 1916 realizada por Caramba y Renato Simoni era una interpretación libre del ballet de Manzotti y Marenco, en la que la trama se desarrollaba desde las tempranas redadas bárbaras hasta el incendio de la catedral de Reims y la invasión de Bélgica (2001: 113). Si tanto el bombardeo de la catedral como la invasión y la posterior ocupación de Bélgica fueron acciones llevadas a cabo por los alemanes, entonces parece claro, en principio, que el lugar de la barbarie estaba en uno de los bandos. Como se puede observar, esta versión está atravesada por uno de los acontecimientos más importantes de principios del siglo XX: la Primera Guerra Mundial (1914-1918). Evidentemente, el conflicto bélico incidió en la modificación de un ballet que entendía que los progresos técnicos de la Humanidad llevarían a la fraternidad de las naciones.

En términos históricos, la Gran Guerra, según nuestra lectura, no haría más que afirmar el lugar de dependencia económica de los países latinoamericanos, lo que llevará a definir una posición neutral en la mayoría ellos, como en el caso de la Argentina. En América Latina, como menciona Mario Ojeda Revah (2014), la conflagración europea "revelaría hasta qué punto los acontecimientos europeos animaron no sólo un debate interno entre las sociedades latinoamericanas, sino que propiciaron una gran transformación social y cultural de las mismas" (9). Con esta afirmación, el investigador desmiente aquella percepción generalizada de que América Latina vio la guerra como un fenómeno ajeno y distante, que no significaba una amenaza para la región.

Con solo observar la cobertura mediática del conflicto bélico se puede constatar lo que menciona Ojeda, es decir, que la lejanía y la ajenidad no eran tales, sino que la cercanía y la preocupación por el tema recorrían las páginas de los diarios. Al día siguiente del estreno de Excelsior, por ejemplo, el diario Crítica publicaba una lista negra sobre "El capital alemán en la Argentina", en la que se incluían más de setenta empresas, sociedades y compañías, entre las que estaban: Bunge y Born, Águila Roja, Brucht y Cía., Hoffmann y Stocker, Martínez de Hoz Hermanos, Sociedad de Tubos Mannesmann Ltda., etc.

La propuesta era conformar un comité aliado que tendría como misión "recorrer los barrios, hacer listas volantes de casas enemigas y repartirlas por los alrededores de estas" (1916, 16 de junio: 3). Sobre Bunge y Born, dice en la misma página: "los que fueron dueños absolutos de muchas cosechas argentinas (...) guardan un respetuoso silencio. Silencio aparente porque en el fondo lo que tienen es miedo a una intervención de la marina inglesa. Esto les arruinaría el negocio". Ahora bien, arruinar ese negocio tendría consecuencias importantes, y de ahí también una de las causas de la neutralidad argentina, ya que, efectivamente, el control de importantes sectores de exportación estaba bajo compañías alemanas. El gobierno de Victorino de la Plaza declaró la neutralidad de Argentina unos días después de comenzada la contienda, el 4 de agosto de 1914. El 23 de ese mes ocurrió el fusilamientos del vicecónsul argentino en Dinant (Bélgica), Rémy Himmer, y en septiembre el de Julio Lemaire, vicecónsul y canciller del consulado general argentino en Amberes, por parte de 
las tropas alemanas de ocupación. En noviembre del año siguiente, se capturaría el buque argentino "Presidente Mitre", por parte de la armada británica. Aun en esos momentos, se mantuvo la neutralidad (Ojeda, 2014: 12).

Así, cualquier conflicto afectaría el comercio exterior (fundamentalmente con Gran Bretaña). En ese sentido, esa neutralidad parecía ser funcional: con Gran Bretaña (ya que podía abastecerla de productos primarios argentinos, sin interrupción, durante la contienda) como con Alemania (ya que permitía evitar la dependencia absoluta con Gran Bretaña o Estados Unidos). Otro factor de la neutralidad tenía que ver con la resistencia a dar a Estados Unidos mayor influencia en la región, de ahí la mantención de la neutralidad a pesar de las presiones norteamericanas (Ojeda, 2014: 14-15).

En la crítica a Excelsior, la guerra se filtra no sólo por lo que sucedía en escena, sino también en el auditorio y en el contexto local general. La crónica de Crítica comienza por confirmar un éxito presupuesto (del mismo modo que las críticas de 1883), y establece un enlace con la primera presentación del ballet en el país. Sin embargo, las aclamaciones del público parecen no ser únicamente por el ballo grande en sí:

El público de Buenos Aires ya ha tenido oportunidad de admirarlo cuando se dió hace muchos años en el antiguo Colón, con un éxito que recordarán los que concurrían en aquella época a las veladas líricas, y podemos adelantar que anoche se repitió el éxito, si bien es cierto no podemos interpretar con sinceridad como producidas exclusivamente por el espectáculo en sí, las delirantes aclamaciones que arrancó de todo el teatro en algunos cuadros y sobretodo en la apoteosis final, pues en ello debió influir, y en buena parte, la evocación de la gran tragedia europea, que adquiere en este espectáculo, momentos de una realidad tal, que fácilmente se explica el entusiasmo que ellos despertaron en el cosmopolita auditorio que concurre a la gran sala, sobre todo a las galerías y paraíso... (Anónimo, 1916, 16 de junio: 4)

De aquí podemos extraer varios datos: se mantuvo el final apoteótico de las naciones en esta nueva edición del ballet, la alusión y realidad que adquiría el conflicto bélico en escena era importante, y el entusiasmo de un auditorio cosmopolita se ubicaba fundamentalmente en las galerías y el paraíso, esto es, en los lugares más económicos del teatro (el hecho que el cronista lo señale pone de manifiesto el funcionamiento de esa jerarquía social al interior del edificio teatral). Más adelante, con respecto a las modificaciones introducidas respecto a la versión antigua, la crónica señala que el público comprendió fácilmente el rol que les correspondía a cada una de las potencias en la simbólica lucha (lo que demuestra el didactismo del ballet a partir de la red dicotómica de significados). Sin embargo, aclara:

No queremos significar con ello que el entusiasmo con que fué recibido el baile sea solamente producto de sentimientos ajenos a toda idea de arte o de belleza, sólo queríamos señalar la influencia que la exaltación de los sentimientos patrióticos provocada por determinados cuadros, pudo tener en el entusiasmo de la concurrencia. (Anónimo, 1916, 16 de junio: 4)

Como mencionábamos más arriba, la primera función de Excesior fue un poco más allá de lo que sucedía en escena. La crónica describe un cuasi conflicto diplomático que merece ser transcripto aquí. Dice:

Y no estamos equivocados al traer el recuerdo de la lucha europea, haciendo crónica del espectáculo de que nos ocupa, pues tenemos noticia que él ha producido un "cuasi conflicto" de carácter diplomático, provocado por el ministro de Alemania, a quien se había informado que existían en el baile algunos cuadros que colocaban a su nación en situación poco envidiable. 


\begin{abstract}
El ministro de relaciones extreiores [sic], el intendente, el señor Da Rosa y otros personajes de la comisión del teatro tuvieron que intervenir para convencer al señor ministro que era exceso de celo de su parte y que para encontrar alusiones hirientes para sus sentimientos patrióticos, era necesario mirar el espectáculo con espíritu prevenido y a través de vidrios de origen netamente teutón.

La empresa y la dirección artística se opusieron, como era natural, a la supresión o modificación de tales cuadros, pues de hacerlo, se hubiera malogrado el conjunto, ya que los cuadros "protestados" formaban parte integrante y de mucho valor y significado en el conjunto.

Así lo comprendió el ministro alemán, que desistió de su reclamación, no sin antes conseguir que la bandera de su patria figurara también en la apoteosis final. (Anónimo, 1916, 16 de junio: 4)
\end{abstract}

Esta alusión es notable, porque permite pensar en un claro posicionamiento político del espectáculo, al haber decidido u omitido la inclusión de Alemania en la representación final de las naciones. Si en la versión de 1883 quienes quedaban en un nivel distinto eran aquellos países no alcanzados aún por el Progreso, en esta de 1916 la exclusión cobra otro sentido. Como vimos en el apartado precedente, los pueblos no europeos, que parecían estar fuera de la civilización, sí estaban representados, pero de manera exótica. Aquí, la barbarie parece estar literalmente instalada en el centro de Europa, y su representación -desde la concepción del espectáculo- parece ser directamente negada.

En ese sentido, este suceso puede ponerse en sintonía con otras modificaciones concretas y de carácter político de Excelsior desde el comienzo de su circulación internacional: en París (Eden-Théâtre, 1883), donde todavía era fuerte el sentimiento anti-prusiano, la bandera, la danza y el himno de Prusia fueron reemplazados por los de Hungría (Pritchard, 2001: 114); en 1885, en Trieste, en la escena de las naciones, las tres bailarinas abanderadas debieron enrollar las banderas italianas, se reemplazó el túnel del Cenis por el de Arlberg (en Austria) y se eliminaron las líneas del himno real italiano cuando colapsaba el último muro de roca (con el fin de evitar el tipo de "manifestaciones clamorosas" que habían ocurrido en Viena anteriormente). Además, se introdujo el himno imperial austrohúngaro que se alternaba con versos de la canción popular "Oh, tu, mi Austria!" (O du mein Österreich!) en la escena de la armonía de las naciones (114); inclusive, posteriormente, este ballo grande celebraría el fascismo, en la versión de Giovanni Pratesi estrenada en el San Carlo de Nápoles el 17 de enero de 1931 (Pritchard, 2001: 113).

Como se puede observar, Excelsior desde sus comienzos (e inclusive desde su concepción internacionalista) perdió su lugar de origen para ser un modelo reapropiado por las países en los que este ballet se escenificaba, vehiculizando, la mayoría de las veces, sentimientos patrióticos y discursos nacionalistas. En el caso de un contexto de beligerancia, y a partir de una versión libre de la temática de este ballo grande, aquellos sentimientos y discursos cobraron mayor volumen e importancia. Lamentablemente, hasta el momento, no contamos con mayor información, pero sería interesante averiguar si en esta oportunidad se incluyó a la Argentina en la apoteosis final y dónde quedó ubicada escénicamente, es decir, al lado de qué países agitó -o no- su bandera.

La crónica citada y algunas otras a las que pudimos acceder enfatizan la "grandiosidad", la "magnitud", la "esplendidez", "lo vistoso" del espectáculo, y señalan, a la vez, que sólo podría realizarse en un teatro de las características, también monumentales, del nuevo Teatro Colón. Mencionan, además, "la variedad de movimientos dentro de la unidad del conjunto", "la disciplina y corrección de los diversos elementos que figuran y el arte y maestría de las 'solistas' y primeras bailarinas" (Anónimo, 1916, 16 de junio: 4), "el continuo movimiento de bailarinas, mimos, figuras simbólicas, 
centenares de personas que se mueven con precisión admirable sin que se note la menor falla" (Anónimo, 1916, 19 de junio: 4) lo que pone de manifiesto un virtuosismo en la ejecución de los movimientos suficientes para asegurar el éxito y mostrar, como menciona Susana Tambutti, "la técnica de los bailarines italianos en competencia con la escuela francesa" (2015: 8).

Al ubicar en escena un contenido belicista que tenía como protagonistas a las naciones europeas, cambia el lugar atribuido a la barbarie. Ya no son, como en 1881, los ladrones del desierto en el Sahara, por ejemplo, o cualquier Otro imaginario que ocupara ese lugar en la dicotomía civilización/barbarie como era entendida hasta ese momento. Si por un lado, esa dicotomía en 1881 parecía unir a las naciones civilizadas del mundo contra la barbarie, la irracionalidad y el oscurantismo, al mismo tiempo también fue construyendo una taxonomía al interior de esa humanidad civilizada: no eran (ni son) lo mismo todas las naciones europeas. Esto llevará, en el plano concreto de las escenificaciones de cada país, a modificar políticamente este ballo grande. Según la hipótesis de este trabajo, fue esa civilización universal indiferenciada, sin origen ni fracturas internas, la que Excelsior construyó en el plano de la ficción. Para 1916, si bien estamos ante una versión libre de Excelsior, aquellas promesas civilizatorias, Gran Guerra mediante, parecen insostenibles. Ahora la barbarie, la irracionalidad y la violencia se encuentran en el corazón mismo de Europa.

\section{Conclusiones provisorias}

En este trabajo hemos intentado dar cuenta de Excelsior a partir del análisis de documentos disponibles y con el apoyo de las últimas investigaciones académicas sobre el tema. Repusimos las características principales del ballet comprendiendo la tradición del ballo grande a la que pertenecía y analizamos la versión modelo estrenada en el Teatro alla Scala de Milán en 1881. Recorrimos, posteriormente, su circulación internacional en algunas de las distintas ciudades europeas y del continente americano donde se escenificó, teniendo en cuenta algunas modificaciones que se le fueron realizando. De esta manera pudimos comprender las escenificaciones en la ciudad de Buenos Aires $(1883,1886,1916)$ formando parte de la circulación global de Excelsior.

Ese arco temporal nos permitió, a su vez, entender las escenificaciones en dos momentos diferentes del mismo período histórico (1880-1916) muchas veces comprendido de manera general, sin tener en cuenta que, evidentemente, no es lo mismo 1883 que el año 1916. El inicio de la Primera Guerra Mundial en 1914, en ese sentido, no puede obviarse, ya que es fundamental no sólo para la comprensión del contexto, sino de la versión libre del ballet.

Para mencionar algunas diferencias: en 1883 Excelsior se presentó en el viejo Teatro Colón (iluminado a gas), en la ciudad de Buenos Aires, que todavía no era la metrópolis moderna del Centenario. Incluso el país aún no estaba totalmente organizado, tanto espacial como jurídicamente (la Ley de Territorios Nacionales, por ejemplo, es del año siguiente). Las campañas al llamado desierto estaban en proceso, aniquilando y arrasando con tierras de los pueblos originarios (bárbaros), lo que en el discurso oficial era entendido como daños colaterales a favor del proceso civilizatorio. Las líneas férreas, tan importantes para el proceso de unificación y comunicación de los territorios nacionales, también se estaban expandiendo, incrementando el valor de las tierras e incorporando más terrenos para la producción agrícola-ganadera de exportación. El estreno de Excelsior en 1916 se realizó en el nuevo Teatro Colón (iluminado con luz eléctrica), espacio que expresaba los valores de las elites europeizantes. Para ese entonces, ya habían pasado los festejos del Centenario de la Revolución de Mayo, el país se encontraba en una posición neutral respecto a la contienda internacional 
que había comenzado dos años antes, y coincidía con los Festejos del Centenario de la Declaración de la Independencia el 9 de julio de 1816. Es decir, el país en general y la ciudad de Buenos Aires en particular, habían sufrido transformaciones importantes. En términos nacionales, para esa fecha, la dominación oligárquica que había tornado ficticia la democracia (Ansaldi y Giordano, 2012) estaba llegando a su fin (las elecciones presidenciales ya se habían llevado a cabo e Hipólito Yrigoyen asumiría el cargo el 12 de octubre de ese año). En términos internacionales, con la Primera Guerra Mundial, Europa dejó de ser vista como modelo a seguir, simbolo de la modernidad y núcleo de la civilización, lo que llevaría a un resurgimiento de los nacionalismos en América Latina (Ojeda, 2014: 26). Así, se produjo un cambio de signo en la dicotomía civilización/barbarie. Es decir, la Primera Guerra Mundial modificó sus referencias tradicionales. Tal es así que, como pudimos observar, el conflicto bélico incidió en el contenido del ballet.

El optimismo y las ilusiones que vehiculizaba Excelsior en 1883 al poner a la Argentina en el concierto mundial de las naciones, podríamos decir que se cerró con la versión de 1916. Los indicadores de la exportaciones, el rol neutral del país en la Gran Guerra, la desaceleración de la expansión de los ferrocarriles por el capital privado (ya que en 1916 se había llegado a los límites de la frontera productiva rentable) (Rocchi, 2000: 26), entre otras cosas, pusieron en evidencia el lugar dependiente del país, e incluso, de las mismas clases dominantes como dominantes dependientes (Ansaldi y Giordano, 2012: 476).

En 1883 la circulación internacional del ballet pareció ubicar a un mismo nivel de progreso a las naciones en las que se escenificaba -en sus diversas versiones. El hecho de traer este ballo grande a la Argentina estableció una sincronía cultural con aquellas ciudades de los países europeos dominantes, que estaba dada tanto por lo que significaba en sí mismo este espectáculo como por, fundamentalmente, el tiempo simultáneo de su representación con otras ciudades de importancia, estableciendo así una homologación de Argentina con Estados Unidos y los países centrales de Europa. Excelsior apareció como un itinerario fantasmagórico que exhibía el progreso del mundo occidental en la sucesión de sus cuadros a la vez que circulaba internacionalmente en diferentes compañías, exhibiendo de ese modo, en distintos países, sus características espectaculares y monumentales.

Sin embargo, como pudimos ver, teniendo en cuenta la inclusión de la Argentina en el mercado internacional, esa igualdad de altura se contradecía con la realidad concreta y con el techo puesto a la posibilidad de establecer un proceso de industrialización fuerte y sostenido en el tiempo y/o de conformar al país en una potencia mundial. En ese sentido, comprender el contenido utópico del ballet, por inversión, permite observar las contradicciones en un país que, en lo concreto, se estructuró en sus relaciones con el mundo bajo una situación de dependencia.

Para finalizar, podríamos decir que lo que trajo la importación de este ballo grande a la Argentina (y a muchos otros países) en distintas oportunidades no fue sólo un espectáculo vistoso, sino quizás varias promesas y utopías. El humo -para decirlo así- de la locomotora del Progreso y de la armonía pacífica de las naciones. 


\section{Dibliografía}

"Adamo, S. (2014). "Dancing for the World: Articulating the National and the Global in the Ballo Excelsior's Kitsch Imagination”. En Abbattista, G. (Ed). Moving Bodies, Displaying Nations. National Cultures, Race and Gender in World Expositions Nineteenth to Twenty-first Century (pp. 143-172). Trieste: Edizioni Università di Trieste.

"Allende, J. F. (1916). “Los animales en el teatro”, Caras y Caretas, (931), p. 45-46.

»Anónimo (1881, 20 de enero). “Excelsior”. En La lberia, p.4 [en línea]. Consultado el 20 de febrero de 2020 en http://hemerotecadigital.bne.es/

»Anónimo (1883, 6 de junio). “Primeiras Representações”. En Gazeta de Noticias, p.2 [en línea]. Consultado el 20 de febrero de 2020 en http://memoria.bn.br/

»Anónimo (1883, 21 de junio). “Excelsior”. En Gazeta da tarde, p. 3 [en línea]. Consultado el 20 de febrero de 2020 en http://memoria.bn.br

"Anónimo (1883, 4 de julio). “Theatros e...”. En Gazeta de Noticias, p. 2 [en línea]. Consultado el 20 de febrero de 2020 en http://memoria.bn.br/

"Anónimo (1883, 3 de agosto). “Los Tehuelches". En La Prensa, s/p.

"Anónimo (1883, 26 de agosto). "Life in New York City. The Beginning of the Theatrical Season. Excelsior”. En The Brooklyn Daily Eagle, s/p [en línea]. Consultado el 3 de febrero de 2020 en https://bklyn.newspapers.com/

»Anónimo (1883, 5 de septiembre). “Diversiones públicas”. En El Nacional, s/p.

»Anónimo (1883, 5 de septiembre). “Teatros”. En La Tribuna Nacional, s/p.

»Anónimo (1883, 6 de septiembre). “Diversiones públicas”. En El Nacional, s/p.

»Anónimo (1883, 6 de septiembre). "El ferrocarril de Mar del Plata á Bahía Blanca". En La Prensa, s/p.

» Anónimo (1883, 7 de septiembre). “Excelsior. La primera noche”. En El Nacional, s/p.

»Anónimo (1883, 6 de octubre). “Dramatic and Musical”. En The Brooklyn Daily Eagle, s/p [en línea]. Consultado el 3 de febrero de 2020 en https://bklyn.newspapers.com/

"Anónimo (1883, 5 de diciembre). "The Ballet. The Girls That Succeed Best”. En Queen Bee, s/p [en línea]. Consultado el 3 de febrero de 2020 en https:// elephind.com/

»Anónimo (1886, 8 de agosto). “Teatros” y “Diversiones públicas”. En El Mosquito, s/p.

»Anónimo (1906, 28 de abril). “Teatros y bellezas”. En Caras y Caretas, (395), p. 68 [en línea]. Consultado el 20 de febrero de 2020 en http://hemerotecadigital.bne.es/

" Anónimo, (1908, 25 de mayo). “El teatro Colón”. En Caras y Caretas, (503), pp. 5556 [en línea]. Consultado el 20 de febrero de 2020 en http://hemerotecadigital. bne.es/

"Anónimo (1916, 15 de junio). “Colón”. En Crítica, p. 4.

»Anónimo (1916, 16 de junio). “Anoche en el Colón. Excelsior. ‘El secreto de Susana'”. En Crítica, p.4. 
»Anónimo (1916, 19 de junio). “Anoche en el Colón”. En Crítica, p.4.

»Ansaldi, W. y Giordano, V. (2012). "El orden en sociedades de dominación oligárquica”, América Latina: la construcción del orden. De la Colonia a la disolución de la dominación oligárquica (pp. 465-480). Buenos Aires: Ariel.

»Antuña, E. M. (1906, 28 de abril). “Argentina, granero del mundo”. En Caras y Caretas, (395), p. 56-57 [en línea]. Consultado el 20 de febrero de 2020 en http:// hemerotecadigital.bne.es/

» Benjamin, W. (2005). “París, capital del siglo XX”, Libro de los pasajes (37-63). Madrid: Akal.

"Ciafardini, H. (1990). "La Argentina en el mercado mundial contemporáneo", Crisis inflación y desindustrialización en la Argentina dependiente (19-39). Buenos Aires: Ágora.

"Cifuentes, M. J. (2008). “Acercamientos y propuestas metodológicas para el estudio histórico y teórico de la danza, Aisthesis, (43), pp. 85-98.

"Compañía Alemana Transatlántica de Electricidad (1910). “Algunos datos históricos concernientes al desarrollo de la electricidad y su aplicación en la Capital Federal". En La Compañía Alemana Transatlántica de Electricidad en ocasión del $1^{\circ}$. Centenario de la independencia de la República Argentina [álbum] [en línea]. Consultado el 13 de febrero de 2020 en http://cdi.mecon.gob.ar/

»Cueva, A. (1977). “El proceso de acumulación originaria” y “El desarrollo oligárquico dependiente del capitalismo", El desarrollo del capitalismo en América latina (pp. 65-100). México: Siglo XXI.

»Destaville, H. (2008). "Mirada sobre el siglo XIX y el siglo XX en sus primeros años”. En Durante, B. (coord.). Historia General de la Danza en la Argentina (pp. 13-25). Buenos Aires: FNA.

»Doré, R. (1883, 16 de septiembre). “Excelsior”. En El Mosquito, p. 3.

»Dorris, G. (2000). “Two Balletic sensations: 'Excelsior' and the 'Ballet of the Nuns"”, Dance Chronicle, 23(3), pp. 329-337.

»Durante, B. (coord.) (2008). Historia General de la Danza en la Argentina. Buenos Aires: FNA.

» Giovannini, M. y Foglia de Ruiz, A. (1973). Ballet argentino en el Teatro Colón. Bs. As: Plus Ultra.

" Gómez Cifuentes, B. (2019). “Escenarios para el progreso: el ballet 'Excelsior' en la Exposición Universal de Barcelona de 1888”, Acotaciones, 11(43), pp. 129155 .

» Halperin Donghi, T. (2005). Historia contemporánea de América Latina. Madrid: Alianza Editorial.

» Liernur, J. F. (1992). “Una ciudad efímera. Consideraciones sobre las características materiales de Buenos Aires en la segunda mitad del siglo XIX”, Estudios Sociales, (2), 103-121.

»Liernur, J. F. y Silvestri, G. (1993). “El torbellino de la electrificación”, El umbral de la metrópolis. Transformaciones técnicas y cultura en la modernización de Buenos Aires (1870-1930) (pp. 9-95). Buenos Aires: Sudamericana.

"Malinow, I. (1962). Desarrollo del ballet en la Argentina. Buenos Aires: Ediciones Culturales Argentinas.

" Manzotti, L. y Marenco, R. (1881). Excelsior: azione coregrafica, storica, allegorica, 
fantastica [libreto]. Milano, Firenze, Roma, Napoli, Londra: Regio Stabilimento Ricordi [en línea]. Consultado el 3 de febrero de 2020 en https://archive.org/

"Manzotti, L. y Marenco, R. (1882). Eden-Théâtre. Excelsior, ballet en six parties et douze tableaux [Programa] [en línea]. Consultado el 3 de febrero de 2020 en https://gallica.bnf.fr/

》Mefistófeles (1882, 6 de septiembre). “Ensayo del Excelsior”. En La Prensa, s/p.

»Morillo Morales, J. (2015). Las Exposiciones Universales en la literatura de viajes del siglo XIX [tesis doctoral]. España: Universidad Nacional de Educación a Distancia. Disponible en: http://e-spacio.uned.es

"Pasolini, R. (1999). “La ópera y el circo en el Buenos Aires de fin de siglo. Consumos teatrales y lenguajes sociales”. En Devoto, F. y Madero, M. (Dir.). Historia de la vida privada en la Argentina. La Argentina plural 1870-1930 [Vol. II] (pp. 222268). Buenos Aires: Taurus.

»Penhos, M. (1995). "La fotografía del siglo XIX y la construcción de una imagen pública de los indios". En AA.VV. El arte entre lo público y lo privado (pp. 109125). Buenos Aires: CAIA.

»Penhos, M. (2005). "Frente y perfil. Una indagación acerca de la fotografía y las prácticas antropológicas y criminológicas en Argentina a fines del siglo XIX y principios del XX”. En Penhos, M. et al., Arte y antropología en la Argentina (pp. 15-64). Buenos Aires: Fundación Espigas.

»Postlewait, T. (1999). “The Hieroglyphic Stage: American Theatre and Society, Post-Civil War to 1945”. En Wilmeth, D.B.; Bigsby, C. (Eds.), The Cambridge History of American Theatre. Volume Two: 1870-1945 (pp. 107-195). USA: Cambridge University Press.

»Pritchard, J. (2001). “Excelsior. Documenti i Sagi, Documents and Essays”, Dance Research, XXI, pp. 108-115.

"Rapallo, A. M. (1969). “Descripción del Teatro Colón”. En Caamaño, R. Historia del Teatro Colón (1908-1968) [Tomo I]. Buenos Aires: Cinetea, 175-182.

"Rocchi, F. (2000). "El péndulo de la riqueza: la economía argentina en el período 1880-1916". En: Lobato, Mirta Z. (dir.). Nueva Historia Argentina: El progreso, la modernización y sus límites (1880-1916) (pp. 15-69). Buenos Aires: Sudamericana.

"Sala, J. A. (1969). “Actividad musical en Buenos Aires antes de la inauguración del actual Teatro Colón”. En Caamaño, Roberto. Historia del Teatro Colón (19081968) [Tomo I] (pp. 19-128). Buenos Aires: Cinetea.

"Scalabrini Ortiz, R. (1975). Historia de los ferrocarriles argentinos. Buenos Aires: Plus Ultra.

"Svampa, M. (2010). “Civilización y barbarie en el siglo XIX latinoamericano”, El dilema argentino: civilización o barbarie. (pp. 33-43). Argentina: Taurus.

»Tambutti, S. (2011). "Reflexiones sobre la danza escénica en Argentina - Siglo XX (ficha 4)", Historia de la danza en Argentina [Material de cátedra], Depto. de Artes del Movimiento, Universidad Nacional de las Artes.

" Tambutti, S. (2015). "Danza en Argentina. El nosotros europeo. Teórico 1". Historia de la danza en Argentina [Material de cátedra], Depto. de Artes del Movimiento, Universidad Nacional de las Artes.

» Teatro Colón (1916). “Excelsior”, “I Pagliacci”, Teatro Colón. Temporada oficial 1916 [Programa de mano]. Buenos Aires: Biblioteca del Teatro Colón. 